\title{
TICKS AND LYME DISEASE
}

ROY JOHN, 754 Woodpark Road S.W., Calgary, AB T2W $2 S 4$

Dealing with ticks becomes a way of life when...

I have taken nature trips along the east coast of Canada and the U.S. since the late 1960s. My dog of that time introduced me to a close relative of the spiders, ticks. I learnt from the locals how to recognize and deal with these pests. In the early 1970 s I began organizing trips to see the rich and varied wildlife, particularly of New Jersey. Ticks became a way of life.

In 1975 a tick-borne disease was reported in humans. It was called Lyme disease after the site of its first discovery, Old Lyme, Connecticut. I slowly became more aware of this problem and developed a real concern when I led a trip of 40 people to New Jersey in the mid 1980 s.

There are about 300 species of ticks worldwide. They can be roughly divided into two groups, the soft and hard ticks. Both can be a problem for humans, but it is the hard ticks that transmit Lyme disease. A typical tick is a few millimetres long, has a large roundish body topped by a tiny head and eight legs. At first it was thought that only one species of tick carried the disease. This is not true, so it is important to know something about the common tick species.

For simplicity we can divide our ticks into two groups, which I will call "Wood" and "Deer" ticks. The Wood ticks include the Wood Tick, Dermacentor andersoni, American Dog Tick, $D$. variablis, Lone-Star Tick, Amblyomma americanum and the Brown Dog Tick, Rhipicephalus san- guineus. These ticks are about one and a half to twice the size of the capital letter "O" in this article and, unfed, they are as thick as a Christmas card. They are brown and somewhat square. These are the most abundant of the two groups.

The second group is the Deer ticks, Ixodes scapularis, I. dammini and $I$. pacificus, all called Deer Ticks. These are much smaller ticks, the size of a lower case "o" or smaller, brown and teardrop shaped. A researcher at Georgia University, Dr. Oliver has proved that the Ixodes scapularis and the Ixodes dammini were the same, with the northern version varying only in colour. Since then Ixodes dammini and Ixodes scapularis are combined as I. scapularis.

Lyme disease is caused by a spiral-shaped bacterium (a spirochaete), Borrelia burgdorferi, named for Willy Burgdorfer who isolated the Lyme spirochete in 1982. This bacterium is allied to those that cause relapsing fever and syphilis. The typical symptoms of infection are a "bull's eye" rash - a red spot where the tick was attached, encircled by a broad red ring, called an Erythema Migrans. This can appear days to weeks after a bite. Other symptoms include fever, headache, dizziness and fatigue. Joints, especially knees, can become swollen and painful. In severe untreated cases, arthritis, heart arrhythmia and paralysis can result. However, keep in mind that only $50 \%$ get the rash. It is terribly misleading to think you do not have Lyme disease because you do not 
have a rash. Besides the general achiness of the early onset of Lyme disease, the symptoms are completely individualistic and host determined. Each patient has a unique set of symptoms and should not discard the possibility of Lyme disease if they do not fit the general pattern.

Lyme disease is treatable with antibiotics as long as it is caught at the early stages. Although tetracycline was believed to be the "cure" for Lyme disease when it was first "discovered" in 1975, it was later proven ineffective (unfortunately many people are still using this drug). Because the bacterium can hide in the central nervous system, severe cases are treated with ceftriaxone that penetrates the blood-brain barrier.

At first the disease was confined to the eastern U.S. seaboard, but it is now found throughout most of North America. It was probably spread by migrating birds (the theory as to its arrival in North America in the first place) or by people transporting pets around the country (or both). If any Lyme disease-free areas exist they will not last long. You cannot escape the disease by leaving the country. It occurs in Europe, the former Soviet Union and the Orient too. Indeed the only place that Lyme disease does not exist is on the two Poles where it is too cold (or in a Saskatchewan winter!). There is now Lyme disease on every continent and island on this earth.

The best defence is prevention. The usual first step is to avoid going into woods and grass, not a real option for naturalists! You can wear light-coloured clothing to make these beasts more visible, especially in the peak tick season of June and July. However, ticks are a problem 12 months a year in much of North America, something to remember when going on a winter vacation. Tuck your pants into your socks and wear long-sleeved shirts. Check yourself and your companions from time to time. I had originally believed that DEET-containing repellents were a good control. About 3-4 years ago in the July issue, Consumer Reports stated that DEET was ineffective against ticks. They are hungry and aggressive and ignore the fact that the repellant makes you smell bad. The only effective chemical against the tick is Permethrin sold in cans (same chemical as used in Lice shampoos). This product is sprayed on clothing. Once dried the chemical acts as a mite repellant (or acaracide). Since the ticks wander, the hope is that it will die on contact as it wanders passed an item of treated clothing even if the victim is wearing shorts. This chemical stays on the clothing until agitated out in the wash. It will not come off if the wearer sweats. The spray is useless on skin since it breaks down on skin within 20 minutes.

Ticks often wander for several hours looking for an ideal spot to feed so they can frequently be picked off before they burrow in. Shower after being out and check yourself thoroughly. Remember to check behind your ears and in your belly button - just like your Mother said. If you are vigilant or lucky enough to find it before it transmits any of the bacteria (it can happen any time during the feeding process) the bacteria can still be forced into the blood stream if the tick is improperly removed. I have generally found them at my belt line although a few have been in my hair. Since the mouth includes a barbed part and the tick forms a cement seal to keep it in place as it is feeding, removal is very difficult. If you discover an embedded tick I have found the best method is to pull at the mouth parts by sliding fine tweezers under the body and grabbing at the mouth. Gently pull with fine tweezers until 
the tick comes free and clean the area with an antibiotic cream. You might lose some skin and sometimes the head breaks off and remains imbedded. Although not the most pleasant result, it runs the same risk as getting a splinter. It does not increase the chance of getting Lyme disease. Just be patient and keep pulling gently. I used to believe you had to paint them with nail polish and fill their breathing holes to suffocate them. If you smother a tick it will relax and retract, however, it puts you at GREAT risk. When an organism dies, it relaxes and releases its body fluids. That includes the bacteria residing in the gut of the tick. A similar reaction occurs if you squeeze the tick's body.

I pulled a live tick (picked up at Beaver Creek, just south of Saskatoon) off my back two years ago. I left in a piece of the mouth and within a few days I had a hard, itchy lump. My physician physically removed the problem, but the itch and pink mark remained for some months. You should keep the tick for identification (I trap them between two layers of clear sticky tape) in case you begin to show symptoms. Remember deer ticks are so small they can easily be missed. Unfortunately the symptoms can be confused with many other diseases and this has led to many misdiagnoses.

Ticks prey on a variety of animals from mice to deer to humans. Ticks normally feed for a couple of days, during which time they swell to many times their normal size (still not very large for a deer tick). Then they drop off their host and continue their four stage life cycle. As they progress through larvae and nymph to adult they climb up vegetation and wait for a victim. When an animal or person brushes by they grab the fur or clothing and hang on. Fortunately not all ticks carry infection and it takes quite a time before the tick finds the right place, becomes imbedded and transmits the bacteria. This means a vigilant person should have no problem. However, if in doubt consult your physician. Ticks also cause Rocky Mountain spotted fever, tick paralysis and ulcerated sores.

There is a close relative of the ticks that only reaches Canada in southern Ontario. This is the Chigger, a microscopic mite that feeds on cell fluid, not blood. I am not aware of any disease associated with Chiggers. Unfortunately they hatch in groups of hundreds. As humans are not their normal host they die within a day or two of burrowing into our skin. The reaction this causes itches unmercifully. Be prepared for a couple of weeks of sleepless nights!

Remember your pets and livestock can suffer too. Check them as well as you would yourself. If the animal shows signs of stiffness or fever consult your veterinarian. There is a vaccine for dogs (but not for humans).

I want to thank Dr. Carol Stolow, Director, Lyme Disease Network of New Jersey for her help in preparing this article and clearing up some of my own misconceptions.

1. BRITISH COLUMBIA Department of Agriculture, "Ticks and Man."

2. NEWSWEEK, May 1989, "Tiny Tick, Big Worry."

3. PFIZER CENTRAL RESEARCH, "Lyme Disease."

4. LYME DISEASE NETWORK OF N.J. Web Site. 